\title{
Citrus Limon Leaves Mediated Synthesis Method for Copper Nanoparticles and its Structural Study
}

\author{
Ravindra Kale ${ }^{1 *}$, Prerana Kane ${ }^{1}$, Priyanka Jagtap ${ }^{1}$, Javed Sheikh ${ }^{2}$
}

\begin{abstract}
In the present age, researchers are having a growing interest in developing enabling technology for the biogenic synthesis of metal nanoparticles (NPs). In present work, we have attempted synchronizing nanotechnology and biotechnology by synthesizing crystalline nanostructured copper particles using a biogenic reducing agent viz. Citrus Limon leaves. Optimization of the process parameters, viz. temperature of the synthesis process, $\mathrm{pH}$ of the metal salt solution and amount of the reducing agent used, was done using statistical tool namely response surface methodology and ANOVA. The size distribution and crystallographic study of the synthesized NPs were done using UV-Vis spectrophotometer, laser diffraction method, transmission electron microscopy, X-Ray diffraction analysis, Fourier transform infrared spectroscopy and energy dispersive X-ray. The NPs deposited lemon leaves were used for dye effluent treatment and the decolorization efficiency was measured. The innovative solution for ecological issues like effluent treatment using an environmentally benign synthesis of novel substrates containing nanoparticles was reported.
\end{abstract}

\section{KEYWORDS}

Citrus Limon leaves, Copper nanoparticles, Green Synthesis, response surface methodology.

${ }^{1}$ Institute of Chemical Technology, Mumbai400019, India

${ }^{2}$ Indian Institute of Technology, Delhi, India.

*Corresponding author: Email:

rd.kale@ictmumbai.edu.in

\section{INTRODUCTION}

Nanotechnology deals with matters at a nanometer scale and is hailed to be an important part of material science in today's world. Nanoparticles are the particles having the nanoscale measurement within 1-100 nm range which decides their feature properties [Gopinath et al., 2013; Gopinath et al., 2014; Elias et al., 2016; Kale and Kane (2019); Kale and Kane (2018)]. Nanomaterials can be engineered to improve the special properties at the nanoscale. The quest for tailor-made materials led to development and applications of various NPs which can be utilized as modifiers to impart various desirable properties to various materials/substrates like polymers, textiles, rubbers etc. Conversion of metal ions to metal NPs involves the use of various synthetic chemicals like reducing and capping agents which do not qualify as green and eco-friendly reagents. The utilization of green chemistry principles in the preparation of NPs resulted in the development of various biosynthesis methods which were found suitable for all types' viz. metal, metal oxides and the metal composite of NPs. Such green synthesis methods are cleaner, nontoxic, and eco-friendly as compared to other methods. Green synthesis of metal NPs involves the reduction of the metal salts by using reducing agents of natural source such as microbes, parts of the plants etc. It can be claimed as a green method as the reduction and capping moieties are derived from the natural source such as plants extracts. Among the various routes of green synthesis of NPs, synthesis of NPs using plant-based extracts attracted many researchers from the other methods mainly because of the ready availability of resources and less cost, eco-friendliness of the process, the possibility of getting a higher yield of NPs and quicker process as compared to microbial reduction [Agrawal, $\mathrm{R}$ et al., 2015; Agrawal, $\mathrm{R}$ et al., 2018; Nam et al., 2016; Iravani et al., 
2014; Logaranjan et al., 2016; Velusamy et al., 2016].

Citrus limon (lemon) belongs to the Rutaceae (citrus family) which is widely grown commercially worldwide for the fruit, the juice of the which is commonly used as a food ingredient and considered to be a good source of Vitamin C for human beings [Tomer, K. et al., 2010]. Synthesis of various NPs using various parts of lemon plant are available in literature [Prathna et al., 2014; Prathna et al., 2013; Prasad et al., 2013; Sujitha et al., 2013; Shukla et al., 2012; Liang et al., 2012; Prathna et al., 2011; Prathna et al., 2011].

Most of the researchers utilized lemon fruits as a source of reducing and capping agents for NPs synthesis; however, the information regarding the utilization of lemon leaves for reduction and stabilization is rather scarce. An eco-friendly procedure for the synthesis of colloidal selenium NPs was reported wherein researchers have utilized leaf extract of a lemon plant as a for the synthesis and the protective effect of synthesized NPs against UV-induced DNA damage activities was reported [Prasad et al., 2013].

In the present work, the novel application of lemon leaves with the projected application in effluent treatment is reported. The lemon leaves were utilized for dual purpose viz. reducing agent for the synthesis of copper nanoparticles (CuNPs) and the substrate for insitu synthesis. The lemon leaves containing CuNPs were studied for their efficacy in effluent treatment mainly in the removal of color from the effluent.

\section{RESULTS AND DISCUSSION CCD ANOVA}

Table 6 exhibited the results of experiments and it specified wide variation in the CuNPs biosynthesis. In run 14 i.e. $7.5 \mathrm{~g}$ of reducing agent, temperature $100^{\circ} \mathrm{C}$ and $\mathrm{pH} 3$ maximum CuNPs synthesis (absorbance 0.4256) was achieved.

Experimental data were subjected to multiple regression analysis with the help of central composite design to explain the role of each variable and their interactions in the biosynthesis of CuNPs. The high $\mathrm{R}^{2}$ value implies a coherent correlation between the observed and predicted values. In the case of absorbance, 0.956973 of the coefficient of determination specifies that $95.6973 \%$ of the changeability in the response was related to the given independent parameter, and only $4.3027 \%$ of the total variations cannot be explained. Adjusted determination coefficient (0.918248) was also near to 1 indicating the high significance of the model [Gaur R., et al., 2015]. Therefore, the response trend analyzed using the model was deemed to be sensible.

To test the suitability and significance of the model ANOVA was employed. For each independent variable significance was determined by F-values and P-values, which are listed in table 1. The P-values is used to prove the significance of the coefficients and to decode the interaction among the factors. The linear and quadratic effects of the temperature and reducing agent were significant as can be seen from the degree of significance, proving that they can act as restrictive parameters and the minute difference in their value will change rate of product production. Additionally, the probability values of the coefficient showed a maximum interaction between the two variables $(0.01)$, indicating that $99 \%$ of the model is influenced by these variables.

The connection between all parameters both dependent and independent as well the optimum levels of amount of reducing agent, temperature, and $\mathrm{pH}$ in order to get the maximum CuNPs synthesis was proposed by a second-order polynomial model (Eq. 1).
Absorbance $=-0.04585-$
$0.00433 A+0.106031 B-$
$0.00445 C-0.00044 A B+$
$0.000253 \mathrm{AC}+5.75 \times 10^{-5} \mathrm{BC}+$
$4.95 \times 10^{-5} A^{2}-0.00782 B^{2}+$
$0.002452 C^{2}$

Fig. 1 showed plots of the response surface curves which evaluated interaction effects and optimum values of the parameters where one 


\begin{tabular}{|c|c|c|c|c|c|}
\hline Source & Sum of Squares & df & Mean Square & F Value & Prob $>$ F \\
\hline Model & 0.13795 & 9 & 0.01533 & 24.7122 & $<0.0001$ \\
\hline A-Temperature & 0.02928 & 1 & 0.02928 & 47.2048 & $<0.0001$ \\
\hline B-pH & 0.00094 & 1 & 0.00094 & 1.51384 & 0.2467 \\
\hline C-Amount of Reducing agent & 0.09685 & 1 & 0.09685 & 156.138 & $<0.0001$ \\
\hline A $^{\mathbf{2}}$ & 0.00263 & 1 & 0.00263 & 4.2408 & 0.0665 \\
\hline $\mathbf{B}^{\mathbf{2}}$ & 0.00269 & 1 & 0.00269 & 4.33606 & 0.0639 \\
\hline $\mathbf{C}^{\mathbf{2}}$ & 0.00065 & 1 & 0.00065 & 1.04158 & 0.3315 \\
\hline AB & 0.00387 & 1 & 0.00387 & 6.23553 & 0.0316 \\
\hline AC & 0.00201 & 1 & 0.00201 & 3.23515 & 0.1023 \\
\hline BC & $6.6 \times 10^{-7}$ & 1 & $6.6 \times 10^{-7}$ & 0.00107 & 0.9746 \\
\hline Residual & 0.0062 & 10 & 0.00062 & & \\
\hline Lack of Fit & 0.00268 & 5 & 0.00054 & 0.76064 & 0.6143 \\
\hline Pure Error & 0.00352 & 5 & 0.0007 & & \\
\hline
\end{tabular}

Table 1: ANOVA for synthesized of CuNPs

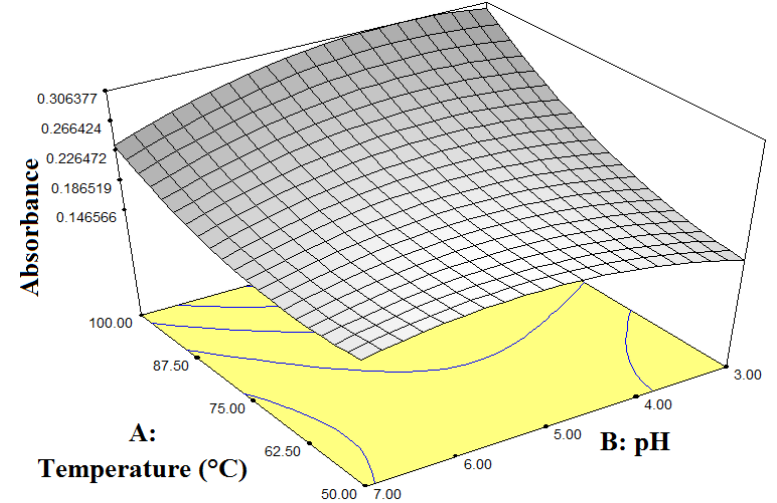

(a)

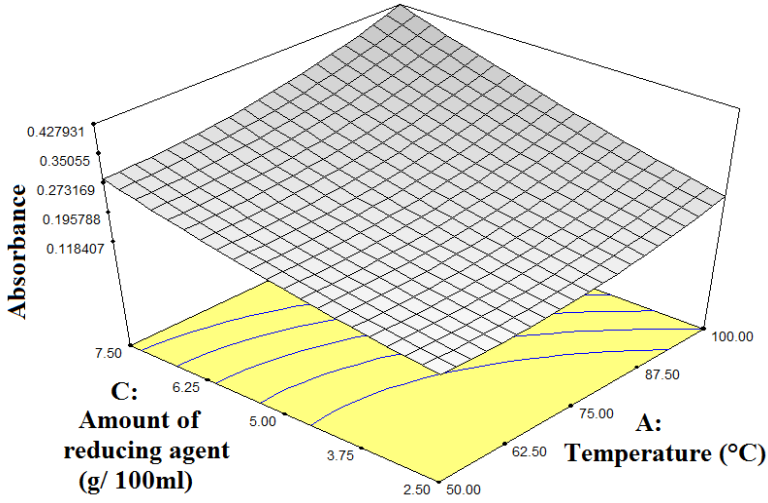

(b)

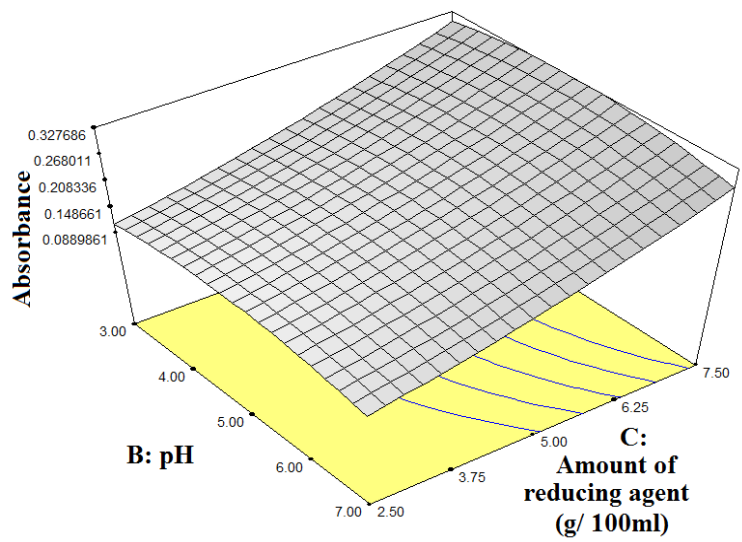

(c)

Fig 1: Response surface carves (a-c) showing the interaction of independent variables on the synthesis of CuNPs. 
parameter kept constant at optimal value and other two parameters are permitted to vary. The interactive effect of independent variables as $A, B$ and $C$ are significant for the CuNPs synthesis showed in Fig. 1. Fig.1 (a) shows, that higher yields of the NPs were achieved at higher levels of temperature and lower levels of pH. Fig.1 (b) showed the higher amount of CuNPs synthesis with an enhanced amount of reducing agent and temperature. The synthesized CuNPs maximum yield appeared at high levels of temperature. Fig.1 (c) shows a higher CuNPs yield which was due to the more amount of reducing agent. In general, the maximum amount of CuNPs was obtained at higher amounts of reducing agent and lower $\mathrm{pH}$.

\section{Model Verification}

Optimum values of the experimental parameter and predicted value obtained from the model were confirmed experimentally. The absorbance at $588 \mathrm{~nm}$ of synthesized CuNPs experimentally was 0.4256 while 0.427457 was predicted by the polynomial model. The verification revealed an accuracy of model higher than $99.56 \%$, which can be considered as a high degree of accuracy indicating validation of the model under given experimental parameters. The optimized parameters for CuNPs synthesis using lemon leaves were found as: $\mathrm{pH} 4.5,7.5 \mathrm{~g}$ of reducing agent and $100^{\circ} \mathrm{C}$ temperature [Hamed et al., 2014].

\section{Optical observation}

The copper chloride reduction could be visually seen by solution color change from blue to green with varying extent of absorbance (Fig. 2) which confirms the formation of CuNPs at $100{ }^{\circ} \mathrm{C}, \mathrm{pH} 4.5$ and with $7.5 \mathrm{gms}$ of reducing agent. The distinctive

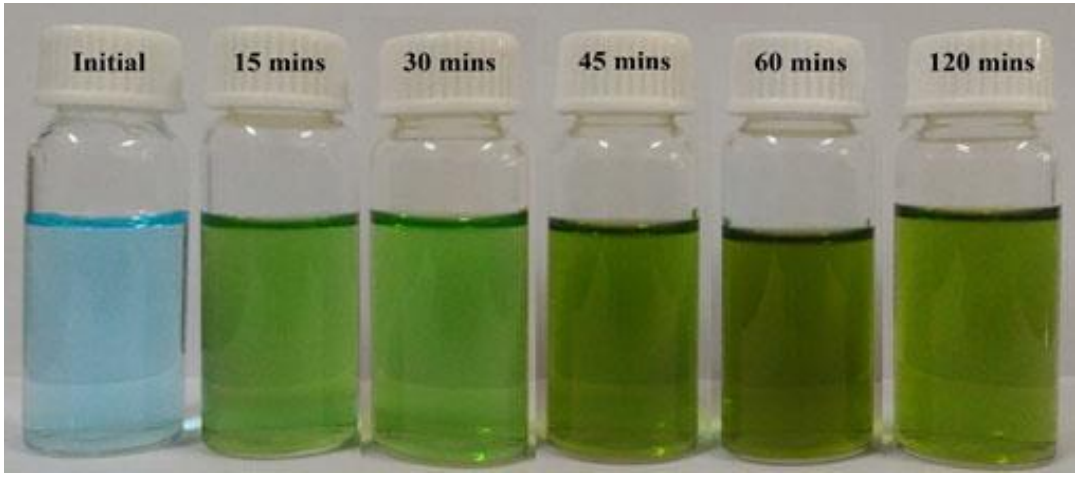

Fig 2: Optical observation of synthesized CuNPs

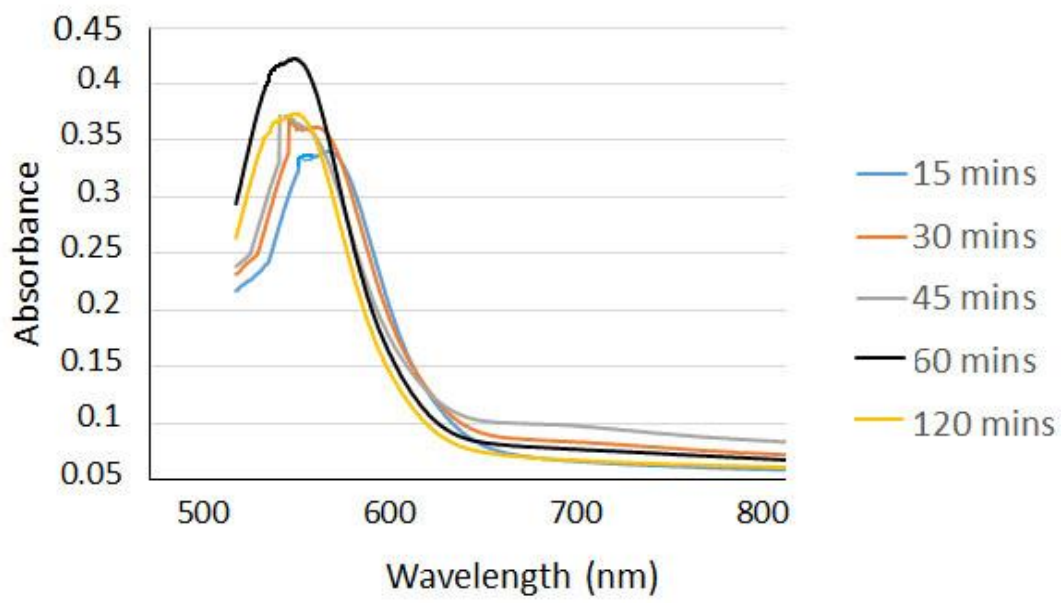

Fig 3: UV-Vis spectrum of CuNPs 
colors of colloidal copper are due to Plasmon absorbance arising due to oscillations in conduction electrons on the surface of the NPs because of incident light which results in absorption of electromagnetic radiation [Krishnaraj et al., 2010]. However, such color changes might also occur due to the variation in the shape, nature, and size of the metal NPs [Shukla et al., 2009].

\section{UV- Vis spectral Analysis}

The UV-Vis spectrum of synthesized CuNPs suspended in the reaction solution for different reaction time are shown in Fig. 3. Absorbance peak in the range of 580-590 nm clearly indicates the formation of CuNPs which was also reported in the previous studies [Caroling et al., 2015; Prabhu et al., 2015]. The $\lambda$ max shifted from $595 \mathrm{~nm}$ to $588 \mathrm{~nm}$ with increasing reduction time from 30 to 45 minutes and for remaining samples, it remained stable at $588 \mathrm{~nm}$ when other experimental conditions were kept constant such as $100^{\circ} \mathrm{C}$ temperature, $\mathrm{pH} 4.5$ and $7.5 \mathrm{gm}$ of lemon leaves. This clearly indicates the optimization of NPs synthesis at 60 mins, after which the gradual decrease in the absorbance was observed.

\section{Measurement of Particle Size}

Figure 4 shows the particle size distribution of the synthesized CuNPs using lemon leaves with $30 \mathrm{~nm}$ as mean particle size. The median of particle size of $29 \mathrm{~nm}$ was confirmed using the laser diffraction technique. The modal particle size was $28 \mathrm{~nm}$ in which more than $90 \%$ particles were below $39 \mathrm{~nm}$ size range, $50 \%$ below $29 \mathrm{~nm}$ and $10 \%$ below $22 \mathrm{~nm}$ range (Table 2). The standard deviation in the measurement of particle size was insignificant (i.e. $0.094 \mathrm{~nm}$ ).

\section{Transmission Electron Microscopy}

From TEM analysis the particle size and morphology of CuNPs were determined. The TEM image in figure 5(a) displays that CuNPs were mainly spherical with a small percentage being elongated to give ellipsoidal shape. The NPs showed a range from $5 \mathrm{~nm}$ to $30 \mathrm{~nm}$ possessing an average diameter of $22 \mathrm{~nm}$. The larger particle sizes indicate agglomeration which could be due to possible sedimentation after a certain period of time. It can also be observed from the images that the particles were somewhat coated with a thin layer, which could be the capping components from the lemon leaves [Tarek et al., 2016]. The CuNPs were crystalline, as visible from the Selected Area Electron Diffraction pattern (SAED). Figure 5(b) was derived from one of the NPs in the aggregate. Different crystallographic planes of elemental copper are SAED spots [Song and Kim, 2009].

\section{X-Ray Diffraction Analysis}

The XRD pattern of synthesized CuNPs is presented in figure 6 . Four discrete peaks were detected at $77.3394^{\circ}, 64.2285^{\circ}, 43.8516^{\circ}$, and $37.5972^{\circ}$ with (311), (220), (200) and (111) Miller indices respectively [Cheirmadurai et al., 2014; Abuhassan, 2009]. These peaks correspond to JCPDS (Joint Committee on Powder Diffraction Standards), copper file No. 04-0836.

It exhibited a crystallinity of $16.2097 \%$ which is corroborated by the sharpness of (200) peak. The plane (200) shifted a little bit towards

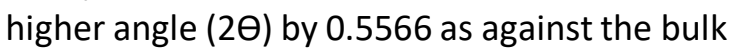
$(2 \theta=43.295$; JCPDS 04-0836) showing compressive stress.

\section{Particle size calculation}

The average particle size as given by DebeyScherrer's formula

$$
D=\frac{0.94 \lambda}{\beta \cos \theta}
$$

Where $\lambda$ is $X$-ray wavelength $(0.15406 \mathrm{~nm}), \beta$ is full-width at half maximum (FWHM) of the diffraction peak in radians, $\theta$ is Bragg's diffraction angle respectively. The particle size obtained was $25.68 \mathrm{~nm}$ [Prabhu et al., 2017]. Calculation of Average Stress in Copper grains The lattice constant of the bulk value $a_{0}$ of Copper is $0.3615 \mathrm{~nm}$ (JCPDS: 04-0836) and the corrected lattice constant in this study was $0.31815 \mathrm{~nm}$ (Table 3, Figure 7) proved that the CuNPs had a strain in its structure. The average stress grown in the sample was given by equation (2),

$$
S=\left[\frac{a_{0}-a}{a_{0}}\right] \frac{\mathrm{Y}}{2 \sigma}
$$


Where $\mathrm{a}_{0}$ and a are lattice parameters of the bulk and NPs respectively.

Y (Young's modulus) $=140 \mathrm{GPa}$ (Copper bulk material)

$\sigma$ (Poisson's ratio) $=0.34$ (Copper bulk material)

The average stress is $24.68 \times 10^{9} \mathrm{~N} / \mathrm{m}^{2}$ [Prabhu et al., 2017].

\section{Dislocation Density Calculation}

The dislocation density $(\delta)$ of sample CuNPs was found to be as $0.151 \times 10^{16} \mathrm{~m}^{-2}$, using equation (3) [Prabhu et al., 2017].

$$
\delta=\frac{1}{D^{2}}
$$

\begin{tabular}{|c|c|}
\hline Cumulative $\%$ & Diameter $\mathbf{( n m})$ \\
\hline 90 & 39 \\
\hline 80 & 36 \\
\hline 70 & 34 \\
\hline 60 & 31 \\
\hline 50 & 29 \\
\hline 40 & 28 \\
\hline 30 & 26 \\
\hline 20 & 24 \\
\hline 10 & 22 \\
\hline
\end{tabular}

Table 2: Cumulative Particle size distribution of CuNPs synthesized using lemon leaves

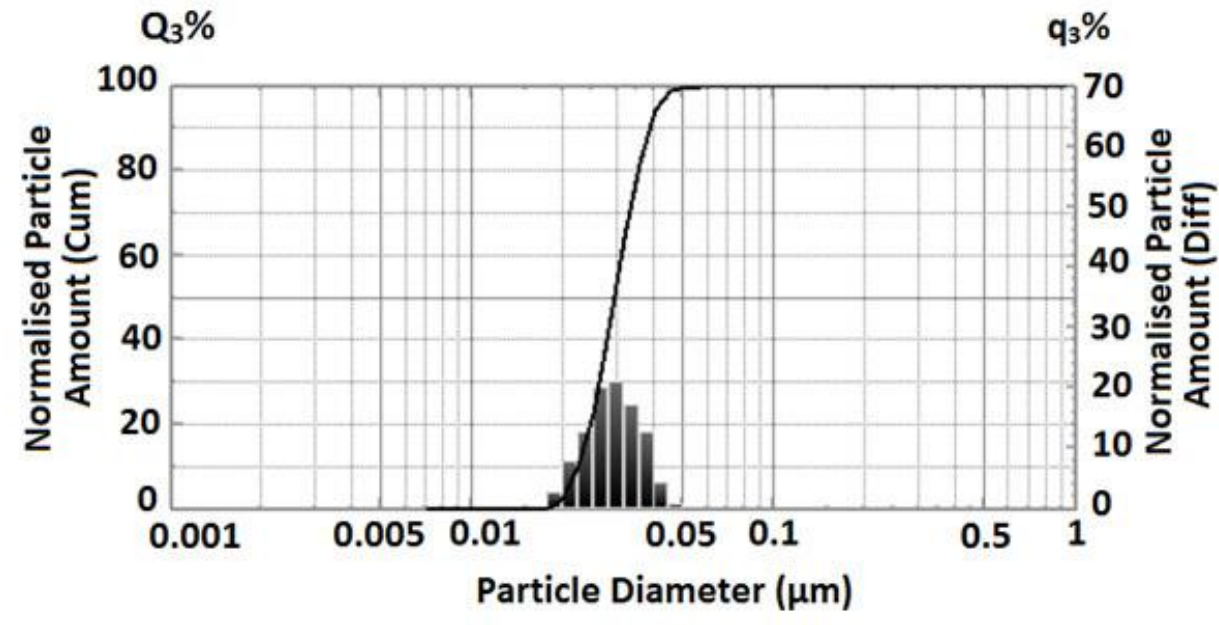

Fig 4: Particle size of synthesized CuNPs

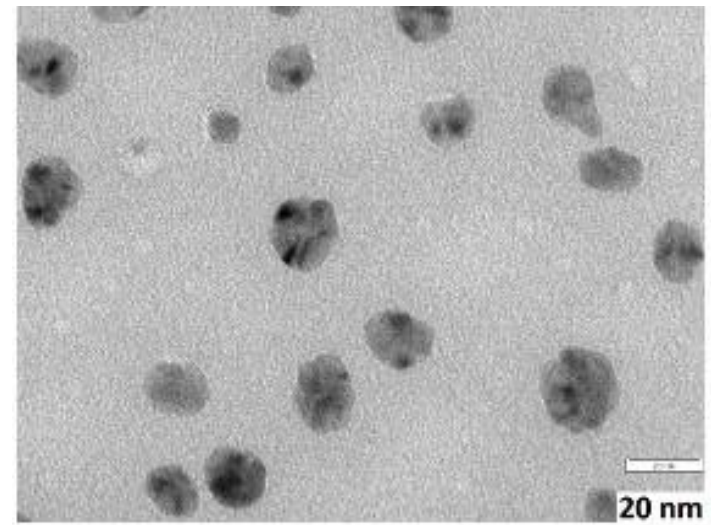

(a)

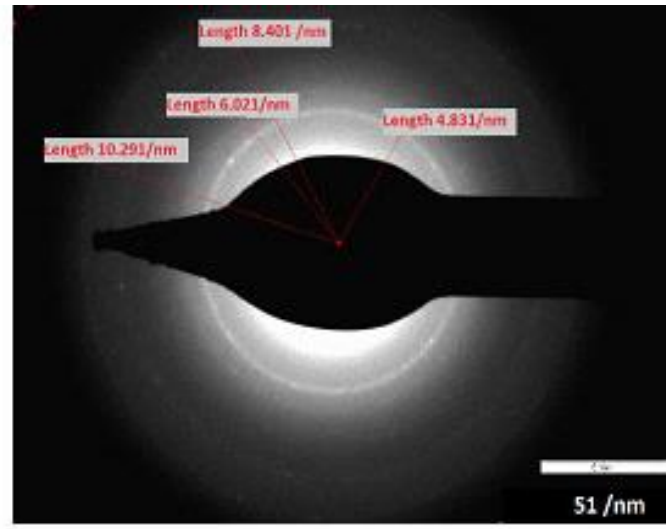

(b)

Fig 5: (a) TEM image of CuNPs (b) SAED pattern of CuNPs synthesized using lemon leaves 


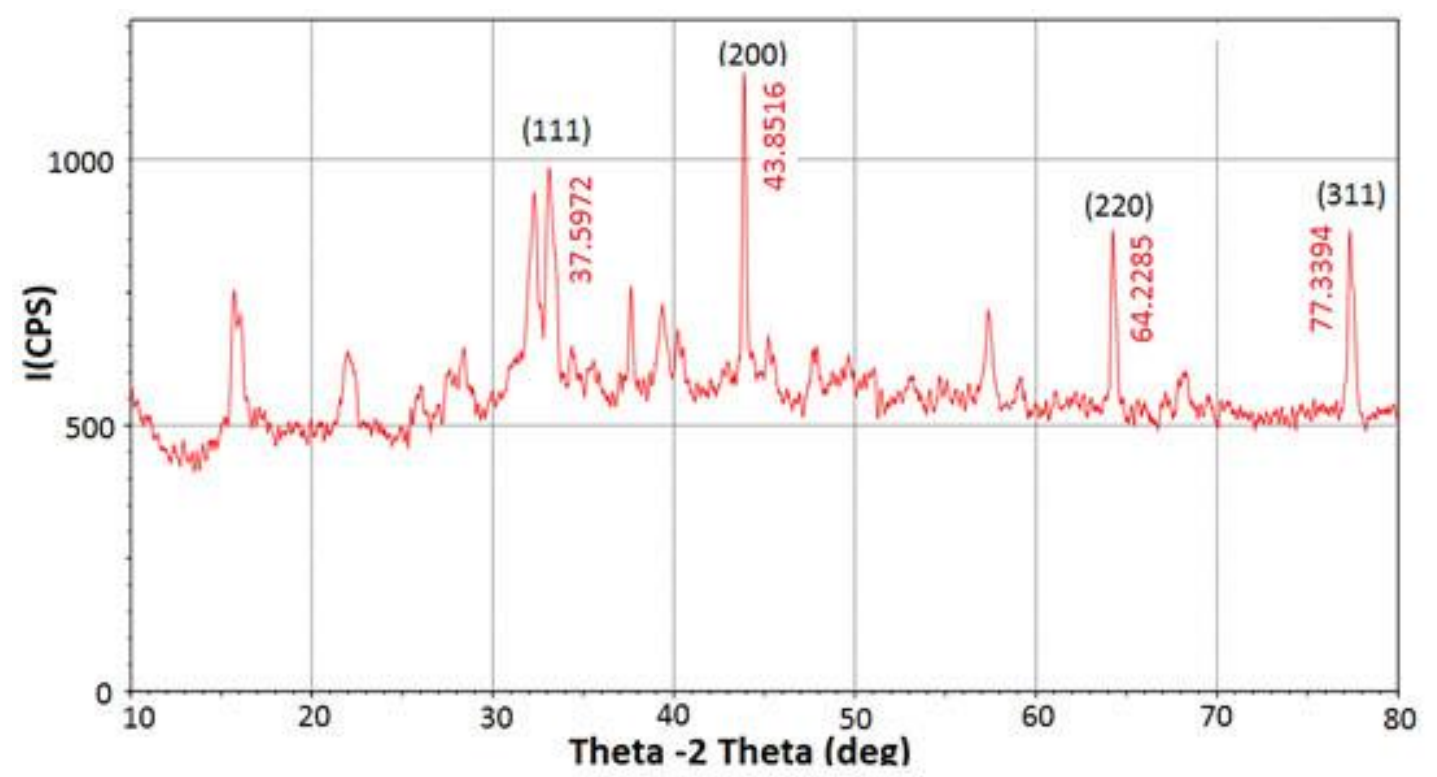

Fig 6: XRD pattern of biosynthesized CuNPs using lemon leaves

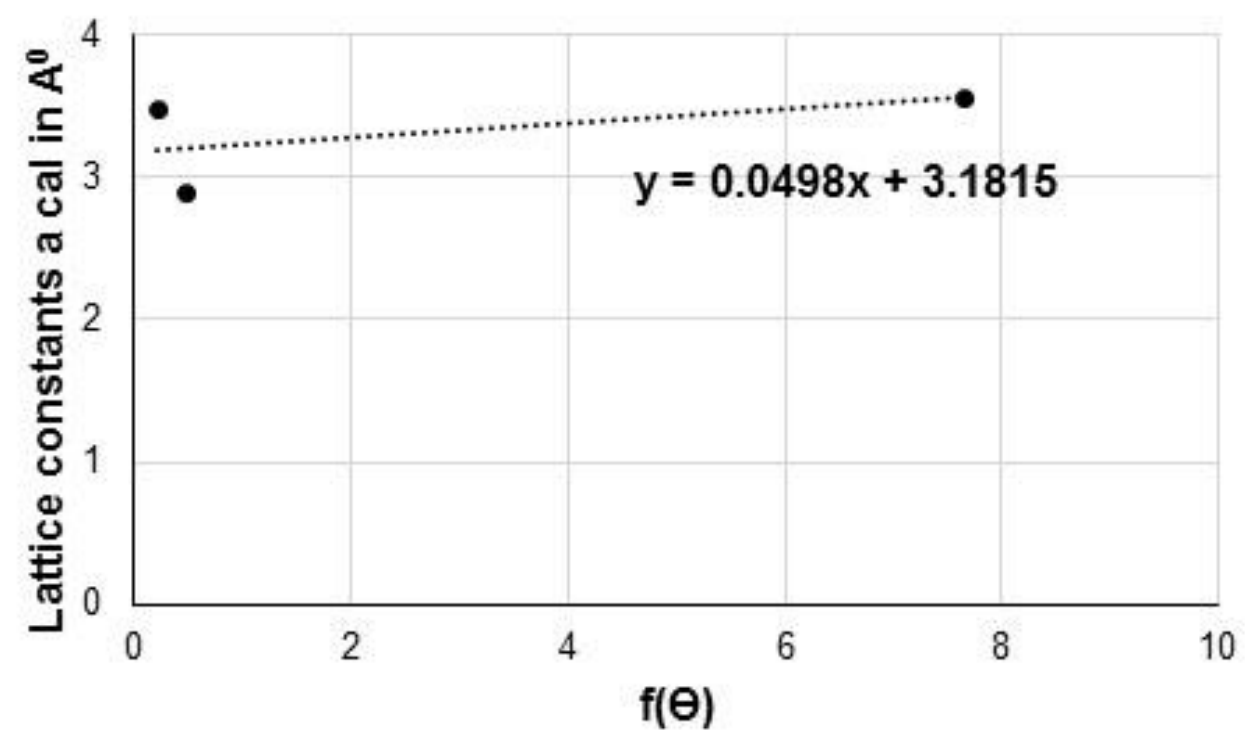

Fig 7: Nelson Riley plot of synthesized CuNPs

\begin{tabular}{|c|c|c|c|c|}
\hline $\begin{array}{c}\text { Plane } \\
\text { spacing } \\
\mathbf{d} \text { (nm) }\end{array}$ & $\begin{array}{c}\text { Crystallographic } \\
\text { planes } \\
\text { hkl }\end{array}$ & $\begin{array}{c}\text { Bragg's } \\
\text { Diffraction angle } \\
\mathbf{2 \theta}\end{array}$ & $\begin{array}{c}\text { Lattice constant } \\
\mathbf{a}_{\text {actual }}(\mathbf{n m})\end{array}$ & $\begin{array}{c}\text { Lattice constant } \\
\mathbf{a}_{\text {corrected }}(\mathbf{n m})\end{array}$ \\
\cline { 1 - 4 } 2.0629 & 111 & 43.8516 & 0.3573048 & \multirow{2}{*}{0.31815} \\
\cline { 1 - 3 } 1.449 & 200 & 64.2285 & 0.2898 & \\
\cline { 1 - 3 } 1.2328 & 220 & 77.3394 & 0.3486885 & \\
\hline
\end{tabular}

Table 3: Structural parameters of CuNPs 


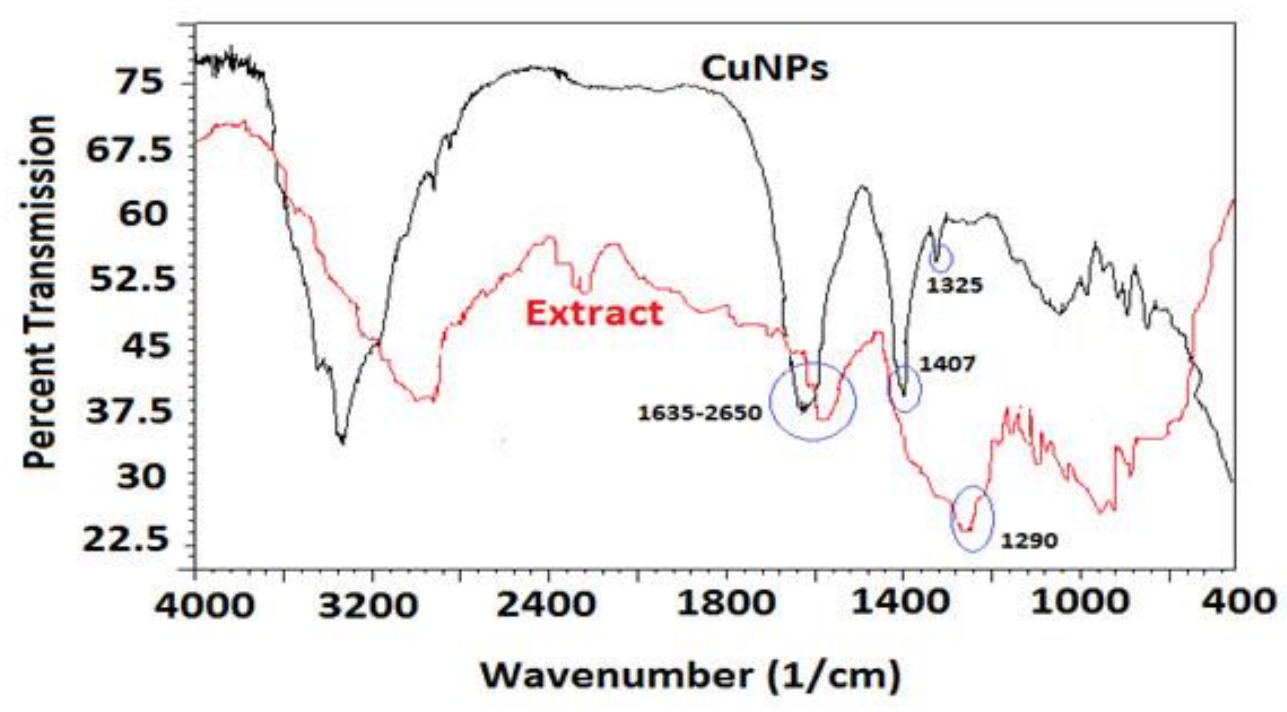

Fig 8: FTIR spectrum of CuNPs colloid and lemon leaves

The calculated crystallite size came closer to the size determined by other methods (Table 4). The larger particle size in case of Laser Diffraction method could be attributed to the tendency of NPs to agglomerate in the colloidal form. For TEM and XRD, the NPs were in dried powder form hence showing lower particle size of the CuNPs. All the methods used for particle size analysis gave the size in the range of 18-29 $\mathrm{nm}$ which were fine enough to qualify as NPs. The method of utilizing lemon leaves as a green reducing agent can be claimed as an efficient method of NPs synthesis.

\begin{tabular}{|c|c|c|}
\hline $\begin{array}{c}\text { Debey- } \\
\text { Scherrer } \\
\text { formula }\end{array}$ & $\begin{array}{c}\text { Laser } \\
\text { Diffraction } \\
\text { Method }\end{array}$ & TEM \\
\hline 25.68 & 29 & 22 \\
\hline
\end{tabular}

Table 4: Particle size ( $D$ in $n m$ ) of CuNPs as calculated by different methods

\section{FTIR Analysis}

The presence of various reducing and capping agents from lemon leaves were analyzed using FTIR. Figure 8 displays the FTIR spectra of the colloidal CuNPs and the lemon leaves extract. It showed presence of peaks at $3334 \mathrm{~cm}^{-1}$, $1631 \mathrm{~cm}^{-1}, 1407 \mathrm{~cm}^{-1}$ and $1325 \mathrm{~cm}^{-1}$.

The presence of amide I band of proteins obtained from the leaves was confirmed by the presence of a peak at $1635 \mathrm{~cm}^{-1}$ which might be the chlorophyll found in the leaf. The chlorophyll is rehabilitated into a number of tetrapyrroles during the de-greening process which can act as the reducing agent [Mathias et al., 2014]. The presence of flavonoids, terpenoids, steroids, and alkaloids in leaf extract was also known. Even though the FTIR results showed the presence of terpenoids and proteins in the leaves, it is quite possible that other biomolecules exist in the solution and reduce the copper ions in addition to its stabilization by capping them.

\section{Energy Dispersive X-Ray Analysis}

For the validation of CuNPs synthesis, EDX spectroscopy analysis was performed by observing the characteristic peaks (Fig. 9). The optical absorption band peak observed at 8 $\mathrm{keV}$ is of metallic CuNPs [Caroling et al; 2015].

\section{Microscopic imaging of the Limon leaves}

The micrographs of lemon leaves were obtained and presented in Fig. 10. The change of color of the leaf was clearly visible after the reaction. This could be due to the deposition of CuNPs on the leaves.

\section{Colour removal of textile effluent with CuNPs} As evident from figure 11, the color of the effluent containing Reactive Blue 171 was decolorized using the lemon leaves containing CuNPs. The decolorization efficiency was found to be $89.23 \%$ which can be considered an excellent level of color removal. 

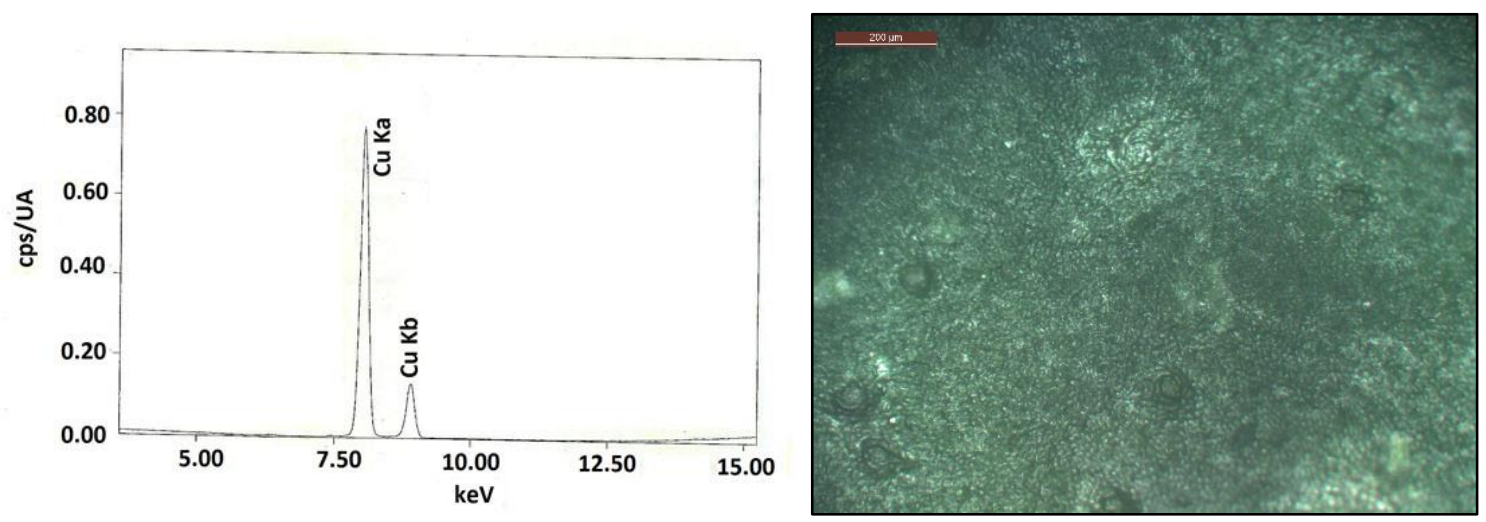

Fig 9: EDX pattern of CuNPs

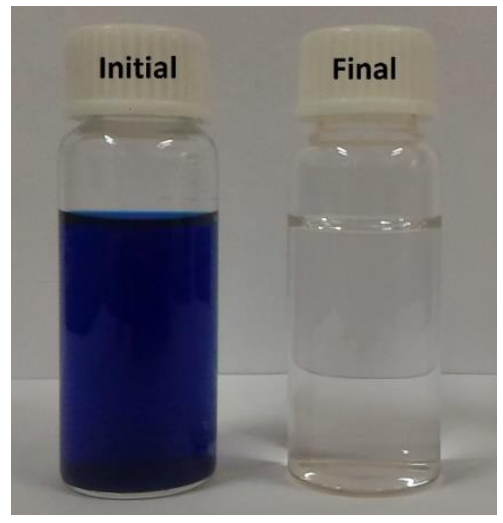

Fig 11: Colour removal of C.I. Reactive Blue 171 using CuNPs deposited lemon leaves

This could be attributed to the presence of insitu synthesized CuNPs on the leaves which can decolorize the dye. Hence, such leaves can find application in the decolorization of the textile effluent. The reported method scores better over the various studies reported in the area of effluent treatment where additional substrates were utilized for immobilization of NPs along with synthetic/natural reducing agents. The waste materials like lemon leaves were made functional using a novel method of modification.

\section{CONCLUSION}

The successful in-situ synthesis of CuNPs was carried out on lemon leaves which also acted as reducing and capping agent. The various parameters were optimized using Design of

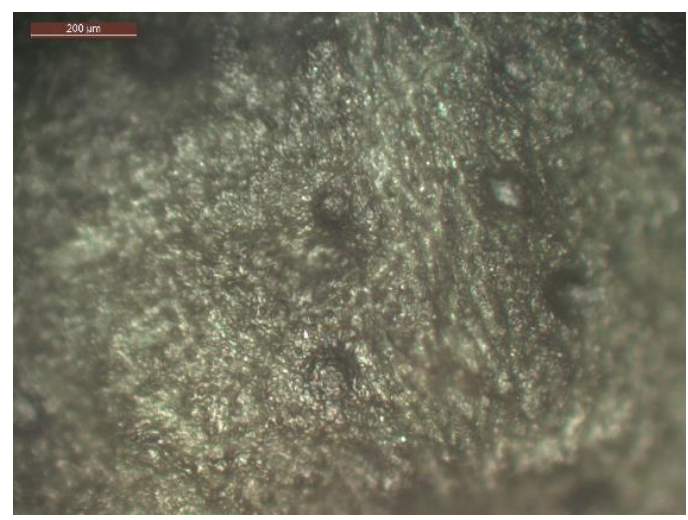

(b)

Fig 10: Microscopic images of lemon leaves (a) before and (b) after synthesis of CuNPs

Experiment. The parameters studied viz. temperature, $\mathrm{pH}$ and reducing agent were found to have a decisive effect on the NPs synthesis. The particle size results calculated by various method was comparable. The shape of synthesized NPs was confirmed as spherical to elliptical. Well-dispersed nanoparticles without agglomeration can be synthesized using lemon leaves. The NPs containing leaves showed excellent efficiency in decolorization of effluent thus showing a great promise for application of such biomolecules in achieving sustainable treatment of effluent.

\section{MATERIAL AND METHODS}

\section{Materials}

Lemon leaves were obtained from the locality of our Institute. C. I. Reactive Blue 171 dye was 
kindly supplied by Atul Industries Ltd, Mumbai. Cupric Chloride dihydrate $\mathrm{CuCl}_{2}$ (Mol. Wt. 170.48) salt, sulphuric acid, sodium hydroxide, soda ash, and Glauber's salt were procured from S. D. Fine-Chem Ltd (SDFCL, Mumbai). All other chemicals used were of analytical grade and obtained from the SD fine chemicals, Mumbai.

\section{Methods}

\section{Synthesis of CuNPs}

Cupric Chloride solution (0.01 M) was prepared in a distilled water. Lemon leaves were washed completely with deionized water, shredded and put into the salt solution. This mixture was constantly stirred at $70 \mathrm{rpm}$ using a shaker bath (Rossari Labtech, Mumbai) machine for two hours. The effect of the amount of lemon leaves, $\mathrm{pH}$ and temperature were studied by performing various experiments according to the Response Surface Methodology (RSM). 0.1 $\mathrm{N}$ sulphuric acid and $0.1 \mathrm{~N}$ sodium hydroxide were used to maintain the reaction solution $\mathrm{pH}$. The NPs synthesis was noted from the solution color change as shown in figure 12 . The solution was filtered after cupric chloride reduction, then stored for further analysis and application.

\section{Optimization of Process parameters}

The optimization of individual variables such as reducing agent concentration, $\mathrm{pH}$ and temperature were done using the optimization tool of RSM. A Central Composite Design (CCD) model was obtained for the 3 dependable variables consisting of 20 experiments which included 8 cubes, 6 central and 6 axial points as shown in table 5 and 6 .

In order to confirm the synthesis of NPs, the absorbance at $\lambda \max$ was measured spectrophotometrically after each experiment. Absorbance was individually taken as responses.

\section{Characterization of CuNPs synthesized using optimum process conditions. \\ UV- Visible spectral Analysis}

The preliminary characterization of the biosynthesized CuNPswas done by UV-Vis spectrophotometer (UV-1800 ENG 240 V, Shimadzu, Japan) with $1 \mathrm{~nm}$ resolution in the wavelengths from $200-800 \mathrm{~nm}$. The bioreduction of $\mathrm{Cu}^{+2}$ in aqueous solution was continuously monitored by regularly taking out samples. UV-Visible spectroscopy analysis of the synthesized CuNPs was carried out over a period of time.

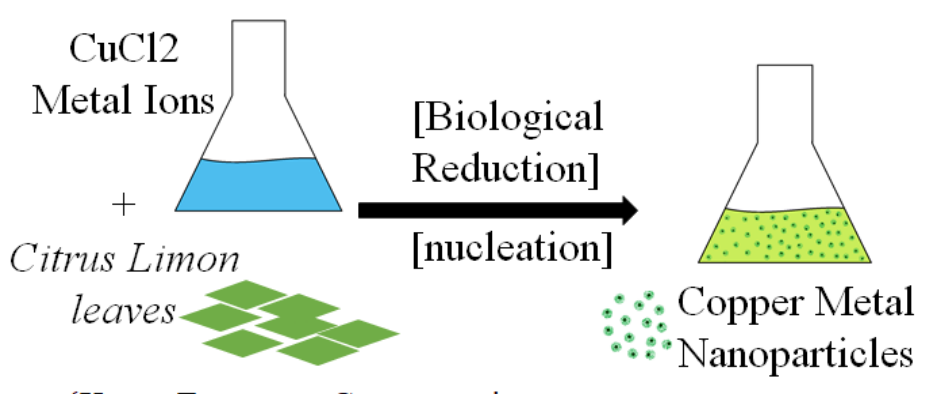

Key Factors: Concentration, Reaction Time and Temperature\}

Fig 12: CuNPs synthesis schematic diagram

\begin{tabular}{|c|c|c|}
\hline \multirow{2}{*}{ Variable } & \multicolumn{2}{|c|}{ Levels } \\
\cline { 2 - 3 } & -1 & 1 \\
\hline Temperature $\left({ }^{\circ} \mathrm{C}\right)$ & 50 & 100 \\
\hline $\mathrm{pH}$ & 3 & 7 \\
\hline Amount of reducing agent $(\mathrm{g} / 100 \mathrm{ml})$ & 2.5 & 7.5 \\
\hline
\end{tabular}

Table 5: independent variable and their levels used for CCD method. 
Table 6: Experimental run with the response

\begin{tabular}{|c|c|c|c|c|c|}
\hline \multirow{2}{*}{ Run } & $\begin{array}{c}\text { Temperature } \\
\left({ }^{\circ} \mathbf{C}\right)\end{array}$ & $\mathbf{p H}$ & $\begin{array}{c}\text { Amount of reducing } \\
\text { agent (g/ 100ml) }\end{array}$ & \multicolumn{2}{|c|}{ Absorbance at 588 $\mathbf{n m}$} \\
\cline { 5 - 6 } & 50 & 7 & 7.5 & 0.2816 & 0.269348 \\
\hline 1 & 75 & 5 & 5 & 0.2433 & 0.213319 \\
\hline 2 & 75 & 5 & 7.5 & 0.3305 & 0.327056 \\
\hline 3 & 75 & 5 & 2.5 & 0.1483 & 0.130236 \\
\hline 4 & 50 & 3 & 2.5 & 0.0835 & 0.079608 \\
\hline 5 & 50 & 5 & 5 & 0.1809 & 0.190136 \\
\hline 6 & 75 & 5 & 5 & 0.2217 & 0.213319 \\
\hline 7 & 75 & 3 & 5 & 0.2119 & 0.191736 \\
\hline 8 & 100 & 7 & 2.5 & 0.1348 & 0.136198 \\
\hline 9 & 75 & 5 & 5 & 0.1673 & 0.213319 \\
\hline 10 & 75 & 7 & 5 & 0.1737 & 0.172356 \\
\hline 11 & 100 & 3 & 2.5 & 0.1825 & 0.200128 \\
\hline 12 & 50 & 7 & 2.5 & 0.1007 & 0.103628 \\
\hline 13 & 100 & 3 & 7.5 & 0.4256 & 0.428048 \\
\hline 14 & 75 & 5 & 5 & 0.2016 & 0.213319 \\
\hline 15 & 75 & 5 & 5 & 0.2143 & 0.213319 \\
\hline 16 & 100 & 5 & 5 & 0.3291 & 0.298356 \\
\hline 17 & 100 & 7 & 7.5 & 0.356 & 0.365268 \\
\hline 18 & 75 & 5 & 5 & 0.1887 & 0.213319 \\
\hline 19 & 50 & 3 & 7.5 & & 0.244178 \\
\hline 20 & & & &
\end{tabular}

\section{Nano Particle Size Analysis}

Particle size analysis was carried out by Laser diffraction technique using particle size analyzer (SALD 7500 nano, Shimadzu, Japan).

\section{Transmission Electron Microscopy}

The solution containing the NPs was centrifuged at 4,800 rpm for 5 minutes and the resulting centrifuge was redispersed in distilled water. This process was repeated thrice. TEM sample of the aqueous colloid of CuNPs was prepared by putting a drop on carbon-coated copper grids allowing the water to evaporate. TEM and selected area electron diffraction data were collected on TEM Model 200 Supertwin STEM (Phillips make) with an accelerating voltage of $200 \mathrm{kV}$ and resolution of $0.23 \mathrm{~nm}$.

\section{$X$-Ray Diffraction}

The purified centrifuged and the redispersed suspension was completely dried at $80^{\circ} \mathrm{C}$. The crystallographic study of the CuNPs was done by using X-ray diffractometer (Shimadzu XRD-
$6100)$ with CuKa radiation using the $2 \theta$ range of $10-80$ ․

\section{FTIR Analysis}

The IR spectra of the lemon leaves and the CUNPs was measured on FTIR instrument in the range of $4000-400 \mathrm{~cm}^{-1}$ (FTIR 8400 S Shimadzu, Japan).

\section{Energy Dispersive X-Ray analysis}

The presence of synthesized NPs was confirmed using EDAX (EDX-720, Shimadzu, Japan).

\section{Microscopic imaging of the used lemon leaves}

The optical determination of the leaves before and after NPs synthesis was carried out using Leica DM EP microscope (Leica DMC 2900), Germany.

Color removal of textile effluent with synthesized CuNPs

The leaves with deposited CuNPs were used for color removal of the textile effluent. $0.1 \mathrm{gpl}$ of 
the effluent stock solution was prepared using C.I. Reactive Blue 171. The CuNPs were added in this colored solution and further stirred for 60 minutes on a magnetic stirrer at room temperature. After completion of the reaction, solution absorbance was measured on UV-Vis spectrophotometer at maximum wavelength $(\lambda \max =620) \mathrm{nm}$. The color removal efficiency was calculated by using equation 4 [Kale and Kane, 2016].

Decolourization $(\%)=$ $\frac{\text { Initial Concentration-Final Concentration }}{\text { Initial Concentration }} \times 100 \ldots$

\section{Acknowledgment}

Authors acknowledge the FIST - DST project, Govt of India and World Bank funded TEQIP-II for providing the machinery for this research project.

\section{Competing interests' section}

The authors declare that they have no competing interests.

\section{References}

Abuhassan, L.H. 2009), 'Synthesis and characterization of copper nanomaterial', Int. J. Nano and Biomaterials, Vol. 2, pp.375-385.

Agrawal R., Semwal S., Kumar R., Mathur A., Gupta R P., Tuli D K. and Satlewal A. 2018, 'Synergistic enzyme cocktail to enhance hydrolysis of steam exploded wheat straw at pilot scale', Front. Energy Res.,

Agrawal, R., Verma, A.K. \& Satlewal, A. 2015, 'Application of nanoparticle-immobilized thermostable $\beta$-glucosidase for improving the sugarcane juice properties', Innovative Food Science and Emerging Technologies,

Caroling G., Vinodhini E., Mercy A. Ranjitham and Shanth P. 2015, 'Biosynthesis of Copper Nanoparticles Using Aqueous Phyllanthus Embilica (Gooseberry) ExtractCharacterisation and Study of Antimicrobial Effects', Int. J. Nano. Chem., Vol. 1, no.2, pp.5363.

Cheirmadurai K., Soma Biswas, Murali R. and Thanikaivelan P. 2014, 'Green synthesis of copper nanoparticles and conducting nanobiocomposites using plant and animal source', The Royal Society of Chemistry, Vol. 4, pp.19507-19511.

Elias E., Elemike E., Olugbenga D., Inyang D., Samuel J., Chinedu O. 2016, '2-Imino-(3,4dimethoxybenzyl) ethanesulfonic acid Schiff base anchored silver nano-complex mediated by sugar cane juice and their antibacterial activities', Journal of Applied Research and Technology, Vol. 14, pp.38-46.

Gaur R., Agrawal, R., Mathur A., Kumar R., Gupta R. P., Tuli D. K. and Satlewal A. 2015, 'Improved saccharification of pilot-scale acid pretreated wheat straw by exploiting the synergistic behavior of lignocellulose degrading enzymes', RSC Adv., Vol. 5, pp.71462-71471.

Gopinath, S.C.B.; Awazu, K.; Fujimaki, M.;

Shimizu, K.; Shima, T., 2013, 'Observations of Immuno-Gold

Conjugates on Influenza Viruses. Using Waveguide-Mode Sensors', PLoS One, Vol. 8, pp.1-10.

Gopinath S.C.B., Lakshmipriya T, Awazu K. 2014, 'Colorimetric detection of controlled assembly and disassembly of aptamers on unmodified gold nanoparticles', Biosens Bioelectron, Vol. 51, pp.115-123.

Barabadi, H., Honary, S., Ebrahimi, P., Mohammadi, M. A., Alizadeh, A., Naghibi, F. 2014, 'Microbial mediated preparation, characterization and optimization of gold nanoparticles', Brazilian Journal of Microbiology, Vol. 45, no. 4, pp.1493-1501.

Iravani S., Korbekandi H., Mirmohammadi S.V., Zolfaghari B. 2014, 'Synthesis of silver nanoparticles: chemical, physical and biological methods', Research in Pharmaceutical Sciences, Vol. 9, pp.385-406.

Kale R., Kane P. 2016, 'Colour Removal using Nanoparticles', Textiles and Clothing Sustainability, Vol. 2, no.1, pp.1-7.

Kale, R. D., \& Kane, P. B. 2019, 'Colour removal of phthalocyanine based reactive dye by nanoparticles', Groundwater for Sustainable Development, Vol. 8, pp.309-318.

Kale, R. D., \& Kane, P. B. 2018, 'Synthesis of PVP stabilized bimetallic nanoparticles for removal of azo based reactive dye from aqueous solution', Sustainable Chemistry and Pharmacy, Vol. 10, pp.153-162. 
Krishnaraj C., Jagan E. G., Rajasekar S., Selvakumar P., Kalaichelvan P. T., Mohan N. 2010, 'Synthesis of silver nanoparticles using Acalyphaindica leaf extracts and its antibacterial activity against water borne pathogens', Colloids Surf. B, Vol. 76, no.1, pp.50-56.

Liang, W., Church, T.L., Harris, A.T. 2012, 'Biogenic synthesis of photocatalytically active $\mathrm{Ag} / \mathrm{TiO} 2$ and $\mathrm{Au} / \mathrm{TiO} 2$ composites', Green Chemistry, Vol. 14, no.4, pp.968-975.

Logaranjan K., Raiza A. J., Gopinath S. C., Chen Y., \& Pandian K. 2016, 'Shape-and SizeControlled Synthesis of Silver Nanoparticles Using Aloe vera Plant Extract and Their Antimicrobial

Activity', Nanoscale Research Letters, Vol. 11, no.1.

Mathias O. Senge, Aoife A. Ryan, Kristie A. Letchford, Stuart A. Mac Gowan and Tamara Mielke 2014, 'Chlorophylls, Symmetry, Chirality, and Photosynthesis', Symmetry, Vol. 6, pp.781-843.

Nam G., Purushothaman B., Rangasamy S., Song J. M. 2016, 'Investigating the versatility of multifunctional silver nanoparticles: preparation and inspection of their potential as wound treatment agents', Int. Nano Lett., Vol. 6, pp.51-63.

Prabhu Y.T., Venkateswara Rao K., SeshaSai V., Tambur Pavani, 2017, 'A facile biosynthesis of copper nanoparticles: A micro-structural and antibacterial activity investigation', Journal of Saudi Chemical Society, Vol. 21, no.2, pp.180185.

Prasad, K.S., Patel, H., Patel, T., Patel, K., Selvaraj, K. 2013, 'Biosynthesis of Se nanoparticles and its effect on UV-induced DNA damage', Colloids and Surfaces $B$ : Biointerfaces, Vol. 103, pp.261-266.

Prathna T. C., Chandrasekaran N., Mukherjee A. 2011, 'Studies on aggregation behaviour of silver nanoparticles in aqueous matrices: Effect of surface functionalization and matrix composition', Colloids and Surfaces $A$ : Physicochemical and Engineering Aspects, Vol. 390, pp.216-224.

Prathna T.C., Chandrasekaran N., Raichur A.M., Mukherjee A. 2011, 'Biomimetic synthesis of silver nanoparticles by Citrus limon (lemon) aqueous extract and theoretical prediction of particle size', Colloids and Surfaces B: Biointerfaces, Vol. 82, no.1, pp.152-159.

Prathna, T.C., Raichur, A.M., Chandrasekaran, N., Mukherjee, A. 2013, Process development for functionalization of cotton with silver nanoparticles synthesized by bio-based approaches, Current Nanoscience, Vol. 9, no.4, pp.479-488.

Prathna, T.C., Raichur, A.M., Chandrasekaran, N., Mukherjee, A. 2014, 'Sunlight irradiation induced green synthesis of stable silver nanoparticles using citrus limon extract', Proceedings of the National Academy of Sciences India Section B - Biological Sciences, Vol. 84, no.1, pp.65-70.

Shukla VK, Pandey S, Pandey AC; Green synthesis of silver nanoparticles using neem leaf (Azadirachtaindica) extract, In: Proceedings of International Conference on Advanced Nanomaterials and Nanotechnology, ICANN - 2009, Guwahati, Assam (India). 9-11 December 2009.

Shukla, D., Vankar, P.S. 2012, 'Synthesis of plant parts mediated gold nanoparticles', International Journal of Green Nanotechnology: Biomedicine, Vol. 4, no.3, pp.277-288.

Yong, S. J., Soo, K. B. 2009, Rapid biological synthesis of silver nanoparticles using plant leaf extracts', Bioprocess Biosyst Eng, Vol.32, pp.79-84.

Sujitha, M.V., Kannan, S. 2013, ‘Green synthesis of gold nanoparticles using Citrus fruits (Citrus limon, Citrus reticulata and Citrus sinensis) aqueous extract and its characterization', Spectrochimica Acta - Part A: Molecular and Biomolecular Spectroscopy, Vol.102, pp.15-23.

El-Desouky, T.A., Ammar, H.A.M. 2016, 'Honey mediated silver nanoparticles and their inhibitory effect on aflatoxins and ochratoxin A', Journal of Applied Pharmaceutical Science, Vol. 6, pp.083-090.

Tomer, K., Sethiya, N. K., Shete, A., \& Singh, V. 2010, 'Isolation and characterization of total volatile components from leaves of citrus limon linn', Journal of advanced pharmaceutical technology \& research, Vol. 1, no.1, pp.49-55.

Velusamy, P., Su, C.H., Kumar, G.V., Adhikary, S., Pandian, K., Gopinath, S.C., Chen, Y. 
Ravindra Kale et al. European Journal of Sciences (EJS), 2019, In Press

\&Anbu, P. 2016, 'Biopolymers Regulate Silver Nanoparticle under Microwave Irradiation for Effective Antibacterial and Antibiofilm Activities', PloS one, Vol. 11, no.6. 